\title{
THE TRACE AND THE GAZE: TEXTURAL AGENCY IN REMBRANDT'S LATE PORTRAITURE FROM A VISION SCIENCE PERSPECTIVE
}

Steve DiPaola

School of Interactive Art and Technology

Simon Fraser University

250-13450 $102^{\text {nd }}$ Ave.

Surrey, British Columbia

Canada

sdipaola@sfu.ca

http://www.dipaola.org

Abstract - This interdisciplinary paper hypothesizes that Rembrandt, reacting to his Italian contemporaries, developed specific painterly techniques, typically not associated with the early modern period that engaged the viewer and directed their gaze. Though these methods were not based on scientific evidence at the time, it can be argued that they are based on a correct understanding of visual perception. Using scientific and critical sources, this paper attempts to support and extend art history theories that artists in the late 'early modern' period developed painterly techniques associated with optics and texture, along side the more established perspective construction, to guide and influence the observer's perception of their work. While discussed in general terms, the paper will focus on faces and portraiture and will analyze Rembrandt's late portraits to support the general thesis.

\section{INTRODUCTION}

It has been speculated that fine art painters have evolved an open methodology, which exploits specific human vision and perception techniques that has only recently been validated through modern cognitive and biological scientific methods. This paper attempts to explore these issues both from a modern science perspective as well as an art history perspective and will shed early light on how these techniques developed and how they may support critical theory in terms of intuitive versus mechanized views of the early modern period and Rembrandt's place within it. It is this paper's contention that artists such as Rembrandt were also using a more organic vision approach to communicate with the observer beside perspective and optical lighting effects.

\section{Early Modern Painting: Monolithic Mechanistic View}

A common notion of the Renaissance is that science and art were very much intermingled. This was the result of the introduction of the scientific method, which provided a new process for discovery, and placed an emphasis on empirical evidence and the importance of mathematics. In Renaissance art, a defining feature was the development of highly realistic linear perspective. This "development of perspective" was part of a wider trend towards realism in the arts.

In his 1998 essay, Harry Berger Jr. [1] describes what he and others saw as a monolithic view in academic discourse on the early modern period. Martin Jay termed 
this view as "Cartesian Perspectivalism" [2] i.e. a mechanized, two-headed dragon of the 'camera obscura' and 'perspective', conjured up from the period's adoption of new scientific ideals, which abstracted and alienated the organic binocular system for a nonorganic monocular system of vision, while Berger called it the cyclopean robot, which as Alberti described in his classic On Painting, "hailed mathematics over physics or physiology" [3], in its recasting of vision. This "prosthetic relocation" of the subjectivity of the observer, attributed to Locke, Hume and Descartes, creates a form of representationalism that removes the organic and re-incorporates the visual into the virtual being. Are other organic forms of painterly intention buried by mechanistic thought during this period? If scientific thought contributed to this mechanized view of vision during this early modern period, can science be once again called upon, albeit in a more modern form, to relocate the eye back to its organic origins?

\section{Systems of Early Modern Painting - Painting Modes}

We again turn to Berger's 'Systems of Early Modern Painting' essay and then onto modern cognitive theory to give us some structures and data to parse through this problem. Berger's System of Early Modern Painting describes four painting modes which give a strong methodological foundation to build upon and, at times, extend. For our interdisciplinary purposes, these modes also have proved uniquely invaluable in that they appear to remain meaningful in both critical and scientific worlds. The four modes are decorative, graphic, optical and textural. The decorative mode uses pigment, colour, light, and technique to not only give a sense of beauty but to honour the painting and the subject. In the graphic mode, subjects are painted as they are known or thought to be, i.e., as people imagine they really are and appear. Lifelike, naturalistic imitation of 3D forms in space and spatial relations are significant in the graphic mode as well as the visualization of knowledge, for instance incorporating the knowledge from anatomical studies. Berger posits that the transition from decorative mode to graphic came as patronage changed from religious clientele to that of the merchant class. In the optical mode, things are painted as they are seen with an emphasis on the conditions of visibility that affect, alter, or in some cases interfere with the graphic mode. In the textural mode, the qualities of paint and the trace of the painter's hand come into play and are interposed between the eye and the image. The textural mode represents the activity of painting, the material qualities of paint and the gestural qualities of the artist's hand become intrinsic parts of the image one sees.

Looking deeper into the optical mode, we see that this mode offers the observer a more active interpretive role than the graphic mode. Therefore in the optical mode, as Marcia Hall states [4], constructs an observer who, "must bring things into focus" and "complete the image with his imagination'. The optical mode brought about a shift from "objective" to a "subjective" set of cues.

The textural mode is about 'the trace' - the work of the brush in "real-time" and as an extension of the painter's own body. It can be seen, in some ways, as an extension of the optical mode within the use of the canvas and paint. The trace can be seen as the painter's interpretive act, which then calls for an interpretive response. Texture generates conflicting modes of observership and can be seen as a window to the graphic mode. Berger claims that the textural mode, "obscures where the graphic clarifies, loosens where it fixes, animates where it freezes, softens where it hardens," however this paper is interested in extending his view of the mode to include a level of agency. Could it be that the textural mode can also enrich, invite, and move the viewer's gaze 
via the artist's intention, so that there is a direct connection between the artist's trace and the observer's perception? Is there a dance started with the artist's hands that leads the viewer through the act of finishing the painting?

In the case of portraiture, it could be said that this artistic methodology attempts to simplify, compose and leave out what's irrelevant, emphasizing what's important in their subject. While seemingly a qualitative task, artists have used known techniques such as relying on source tone over colour to indirect into a colour temperature model, using "sharpness" to create a centre of interest, using edges to move the viewers gaze, and other techniques to filter and emphasize their varied goals. One specific technique, associated with 20th century painting, is to use painterly brushwork on the textural plane to direct and coerce the viewer's eye gaze through a painting, thereby influencing the observer's eye movement paths and fixation points within the work. Well known portraitist John Howard Sanden [5] describes his technique of using centre of focus sharpening techniques to move the viewer's eye gaze to the sitter's left eye and eyebrow to emphasize an intrinsic element of the sitter (Figure 1). Sanden also creates a textural spiralling path into this accentuated eye area by using loose directional brush stokes under the eye which follow the asymmetrically curved mouth edge. Exploiting the tendency for eye gaze to follow a line or edge, artist Harley Brown demonstrates in Figure 2, the 'lost and found edges' technique where an edge once followed by the observer's eye can be lost to move the eye into the image [6]. While there are several examples in Figure 2, the most blatant is the lost elbows, which lead you into the downward-looking face. How these textural agency techniques work in a cognitive sense is still an area of research, since they work at the very edge of consciousness or at a strongly intuitive level - both from an artist and observer point of view.

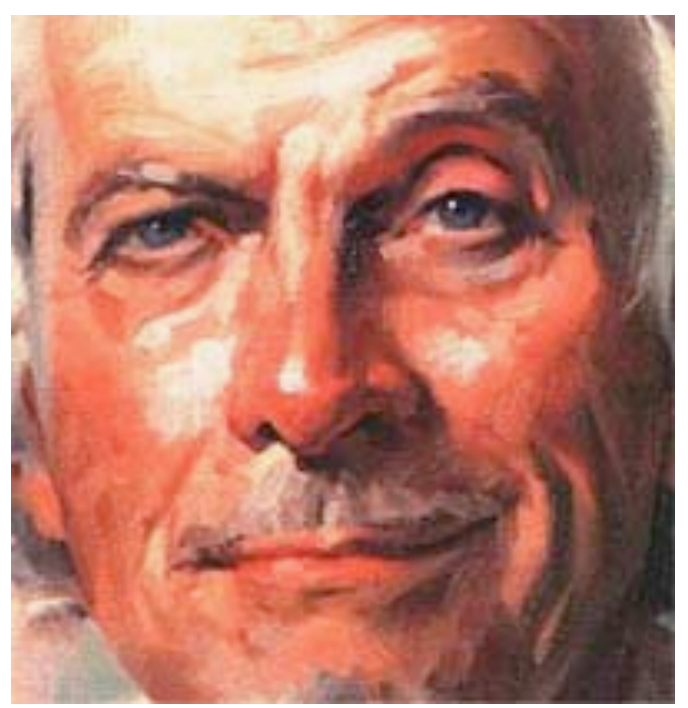

Figure 1. J.H. Sanden, Focus and Paths

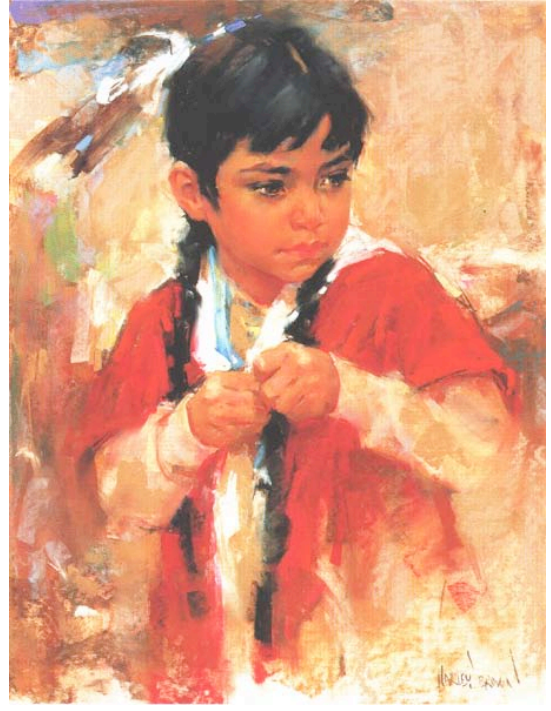

Figure 2. H. Brown, 'Lost \& Found Edges'

Few artists embraced this use of texture during the early modern period like Rembrandt. In his book, Fictions of the Pose: Rembrandt Against the Italian Renaissance, Berger [7] uses Rembrandt as a vehicle to demythologize a more standard view of the intellectual and cultural history of the early modern period. One of Berger's main points concerns what he thinks "the Rembrandt look "sees"'. What Rembrandt sees, challenges, critiques and at times parodies is "the embarrassment of the 
Renaissance riches" of the Italian model. Berger asserts, expanding on Kenneth Clark [8], "Rembrandt transformed his style by the study of Italian Renaissance art". This dialogue, one-directional as it may seem, between Rembrandt and Italy gave way to both a classical and anti-classical style in Rembrandt's art and, more importantly, shifted the discourse in the other direction, reading Italy through Rembrandt's eyes. Berger shows us the process by which painters can "imitate, emulate, appropriate, and sublate" prior art and, more specifically, Rembrandt's performative mastery of this process. Berger refers to this as "revisionary allusion" which allows Rembrandt's implied reconstructions to "creatively distort the past" in order to make it reflect the present and "more immediate(ly) focus on critique". Rembrandt also used a similar approach to critique his interpretation of patronage as well as "the Italianism residing in the Dutch scene of patron / painter relations".

The adoption of oil painting as a medium was controversial when it first appeared. Titian quickly recognized its merits, and added several innovations to early oil painting techniques. While the control of oil with stiff brushes allowed for quite hard edges, Titian apparently found the softer edge techniques more to his liking, and used them extensively, as they gave the effect of being slightly out of focus. The fact that the mature Rembrandt was deeply influenced by 16th-century Venetian painting especially by Titian and Giorgione - wasn't new when Kenneth Clark [8] published his classic study on Rembrandt and the Italian Renaissance. Rembrandt never went to Italy. But Italy came to the prosperous art houses of Amsterdam in the form of what Clark described as 'almost unbelievable quantities' of paintings, drawings, etchings and prints. Historians note that Rembrandt's own voracious art collecting clearly contributed to his bankruptcy in the 1650s. When an inventory was taken of Rembrandt's possessions, an album was devoted almost entirely to Titian's work in Rembrandts collection. As Vasari noted, Titian's late works were "carried out in bold strokes, broadly applied in great patches in such a manner that they cannot be looked at closely but from a distance appear perfect". Noted historian Rosand [9] described the appeal of these late paintings as "tactile as well as visual, inviting us to touch as well as to look. Such synaesthesia informs our response to them, and it was central to the experience of their making." A 17th-century Venetian critic Marco Boschini, which claims to report the words of a late16th-century disciple of Titian writes that toward the end of Titian painting process, he painted more with his fingers than with the brush, comparing himself to God, who also, in forming this human body, created it out of earth with his hands [10]. Titian never taught his assistants; he never gave instruction, but, as Vasari reports, each disciple took whatever he could from the master's example. The same can be said for Titian's most significant followers, like Rembrandt. Rosand describes how "Titian's facture, for all the revelation of his textured surfaces, continues to remain just beyond the reach of comprehension. In comparison, Rembrandt's technique seems quite straightforward, much more accessible to direct visual analysis." We know that Rembrandt revered and emulated late Titian. In typical Rembrandt style did he appropriate and extend Titian's process of textural and bodily touch where touch became while still gestural, a deep communication link to the eye gaze of his viewers. To examine this question in more detail, it is essential to have an understanding of what we now understand of human visual perception and cognitive science.

\section{THE SCIENCE OF HUMAN VISION AND EYE GAZE}


What does modern cognitive science have to offer in light of Berger's discussion of the four modes of Early Modern Painting? We see the world as light enters our eye, passing information through to our visual cortex before being assessed in our associative cortex. The visual cortex processes low level visual constructs such as lines, edges, contours and shapes. These low level constructs are built up in our associative cortex into high level constructs such as patterns, objects, scenes and high level knowledge interpretation. In the human eye, light is sensed through two light receptors - rods and cones. Humans see the world using rods and cones using a central vision strategy.
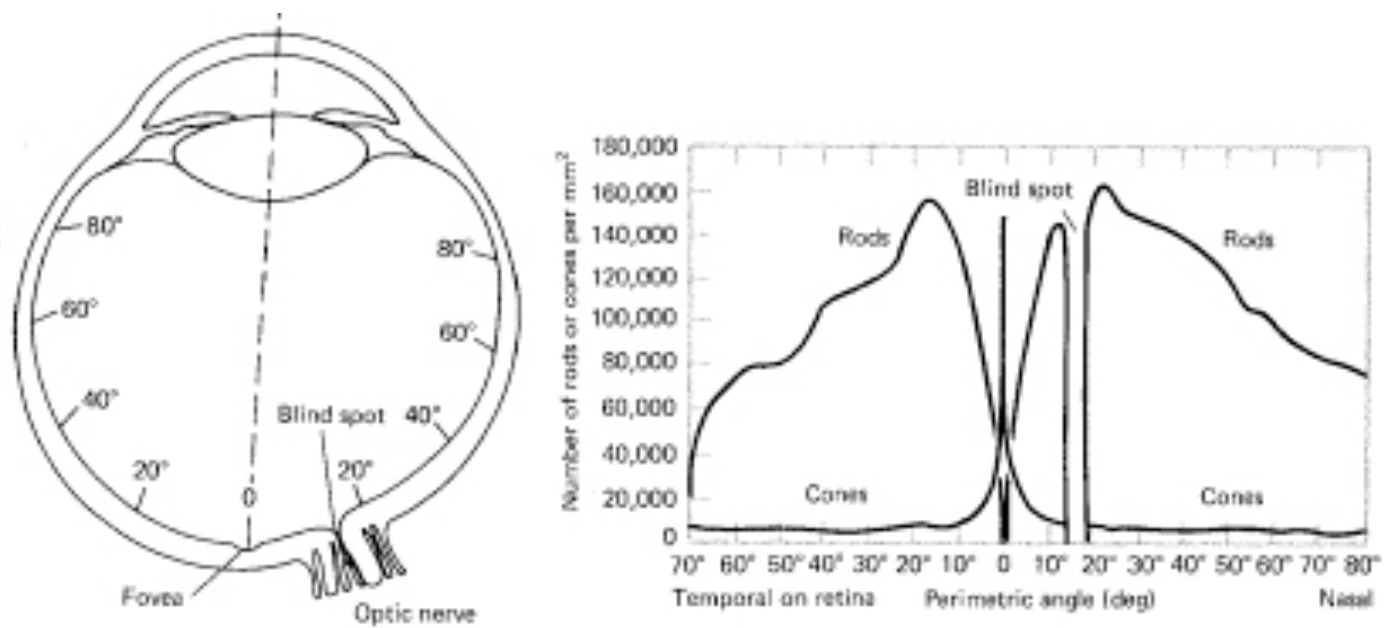

Figure 3. (a) The fovea's size and placement in the eye. (b) The middle spike and fast fall off show the fovea's highly packed density of cones compared to the rest of the eye.

Opposite the pupil is the fovea (Figure 3a), which is a small area more densely packed with cones than the rest of the eye (Figure $3 b$ ). The fovea is the size of a pinhead yet it is our window to the outside world. Humans have one fovea paired with very fast eye muscles, so concentrate most of their visual acuity at one central point, giving us maximum focus when we need it but also mandating that we sample our world through eye movement. The fovea accounts for only 2 degrees of a human's 180 degree vision, roughly equivalent to the viewing area of the nail of a thumb on an outstretched arm. The fovea is surrounded by the next area of vision called the Parafovea which has 10 times less legible than the central fovea. The near peripheral, at $60^{\circ}$ of vision and peripheral at $180^{\circ}$ of vision, are each 10 times less legible than their inner neighbour.

\section{Dynamic Vision and the Eye-brain Loop}

Our 'central focused' vision system requires humans to sample the world with constant eye movement and is referred to as 'dynamic vision.' We see the world, and therefore art, with eyes that are constantly refocusing on different regions. Six muscles on three sides of the eye tirelessly contract and relax in pairs to move our eyes at high speeds, both under unconscious and conscious control. These rapid eye movements, called saccades, were first described by French ophthalmologist Louis Javal in 1878, based on his observation that school children's eyes jumped rather then moved 
continuously when reading. He noted that eyes made short rapid movements intermingled with short stops called fixations. These fixations are the hold times we use to take in a visual sampling of the world, and are very quick, lasting from 200 to 250 milliseconds. Serious research in eye movement did not begin until this last century due to the need for fast eye tracking measurement equipment. Currently there is great interest in recording and analyzing eye movements under different criteria as a way to interpret the human cognitive process, because it appears that eye movement can foretell the mind's volition, intention and attention.

As counter-intuitive as it may seem, humans are incapable of 'seeing' an entire scene; they build up an internal model of the visual scene in front of them through thousands of fixations. This is referred to as the Eye-brain Recursive Loop [11], and more recently has been named the 'internal model hypotheses' where a rapid feedback loop occurs. The brain receives pin-hole sized focused visual data to incrementally build up an internal model from the last fixation, as it gives out instructions to the eye where to sample next. We therefore piece our world together by consciously sampling paths through it. This loop (i.e. saccade move, fixation hold, and reasoning) is amazingly fast, approximately 300 milliseconds between each eye-brain iteration. How controlled this rapid decision making is, is still an active research question, but scientists agree that it is consciously controlled but seemingly right on the edge of human intuition.

\section{Eye Movement Research in Art}

Research towards analysis of art has only begun in the last 40 years. Based on the current understanding of visual perception, we do not see a painting all at once but form an impression from a large number of eye fixations looking at small details.
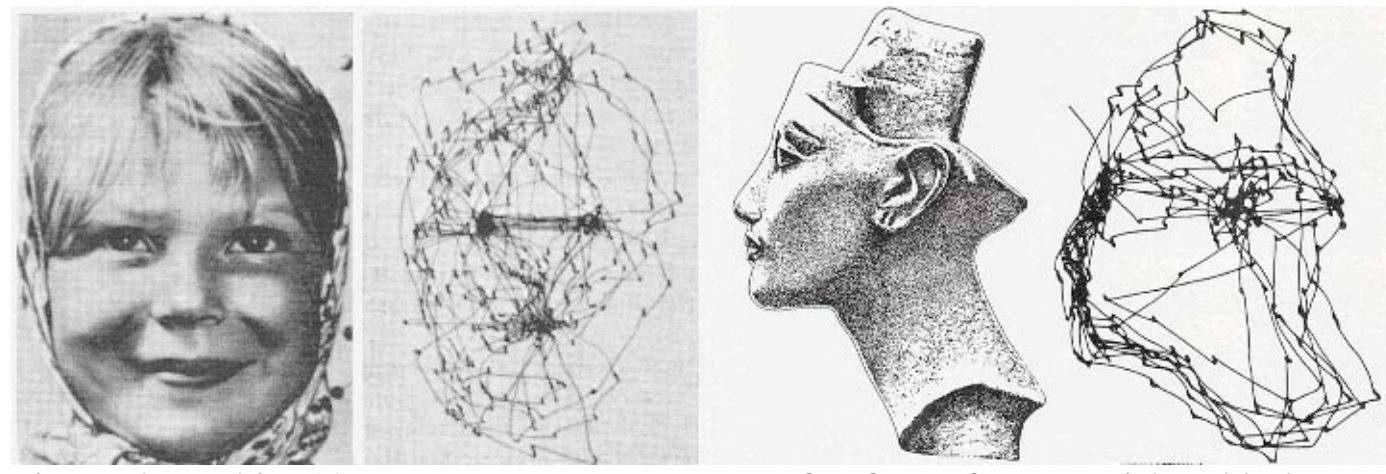

Figure 4. Yarbis [12] Eye movement: Images of a: face of young girl and b: bust of Queen Nefertiti along with the eye scans, both movements (lines) and fixations (points).

Eye movement research is still in its early stages since the processes at work are very complex and measuring devices for eye movement are still fraught with issues of precision, intrusiveness and complicated data analysis. It was even more so in Russia in 1967 when Yarbis using primitive equipment performed some of the first eye movement research in the visual arts. He assembled a study where a test group of subjects viewed, for three minutes, images of a bust of Queen Nefertiti and the face of a young girl. With Queen Nefertiti (Figure 4b), the eye scan paths show that a viewer's eye gaze moves into the image, usually coming from the left, then stops and is diverted by the strong edge contour of the object, following the edge around the bust. Eye gaze moves into the bust at specific points such as through the eyes or following the horizontal edge behind the ear. Most of the gaze follows the contours at the face side of 
the bust. In the face of the young girl (Figure 4a), eye movements are so universal that we can recognize the face just by looking at the scan of the eye traces. Eye movements appear to be a window into the viewer's thoughts and tend to follow edges and contours but also centre on high level constructs like eyes. This was made even clearer by Yarbus' later studies using Repin's oil painting titled 'Unexpected Visitor.' Subjects were asked to view the painting for several minutes, but this time were given seven different goals while they viewed the image. In general, what was apparent was that the viewer's gaze flowed to the faces and was affected by edges and contours. This pioneering work confirmed through scientific methods what artists have appeared to intuit and exploit in their artwork through generations.
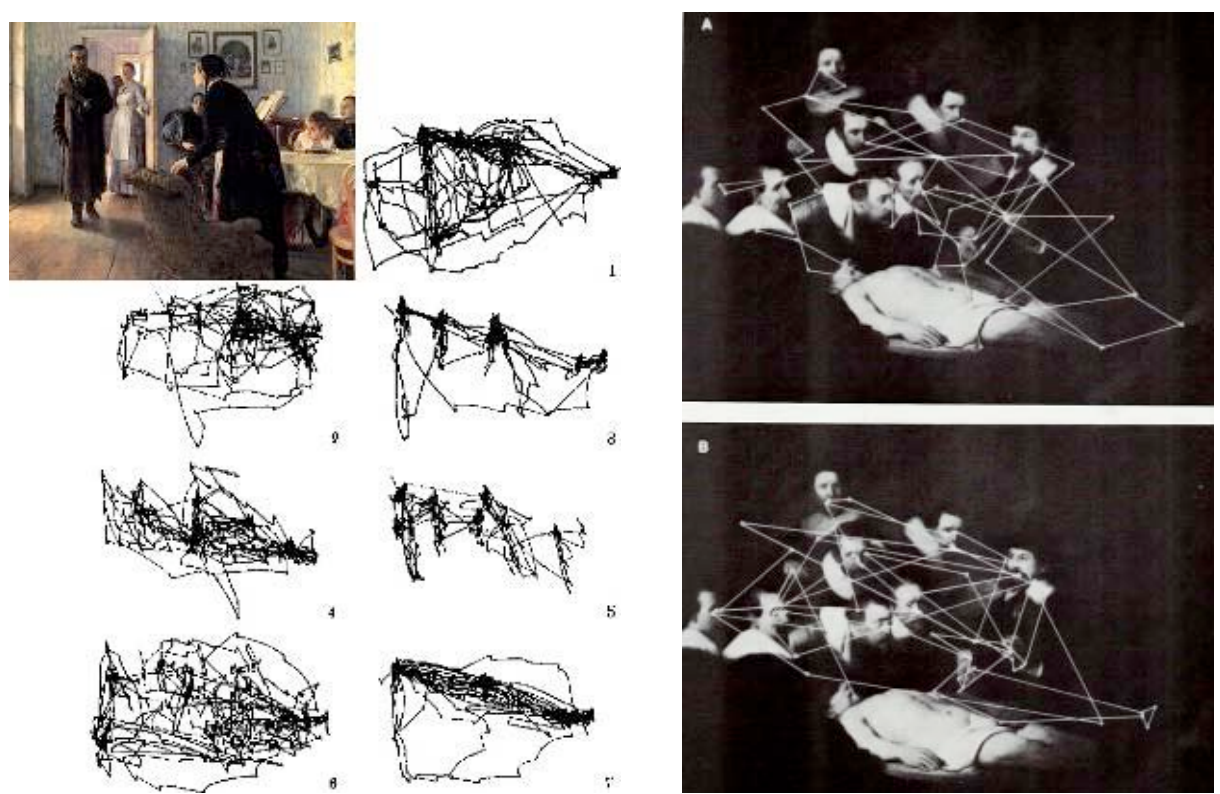

Figure 5. a) Yarbis [12] Repin, 7 targeted scans. a) Molnar [13] Rembrandt, 2 scans.

Over a decade later, Molnar [13] separated art students into two groups as they viewed 'The Anatomy Lesson' by Rembrandt. One group was told to prepare for questions on (Figure 5b top) aesthetic qualities of the painting, the other was told to prepare for (Figure 5b bottom) semantic meaning. Molnar was surprised by the similarity of the scans of these different groups. Molnar reasoned that the similarity might be explained by the fact that both groups were experienced with artistic conventions like background and style. But the general hypothesis of this paper is to question if Molnar might have underestimated Rembrandt's own techniques within the painting to affect eye gaze. These cues by a master painter might have influenced the two groups over the simple initial questions asked by Molnar.

Two points need to be addressed before we bring this section to a close. The first is that we are implying no direct link between the science of central vision, eye movement and art reception with late Rembrandt and other artists in the early modern period. We are simply presenting an overview of how science can bring some clarity and food for thought to this uniquely intuitive and human process of how we view our world and art. The second point worth noting is that these very early studies in eye movement and art, together with a handful of others are the precious few we have on this illuminating area. Even with these few examples, a model unfolds of how humans put a scene together and the influence of low-level constructs like edges and contours together with high- 
level constructs such as faces, people, objects and light, which can deeply affect how we move through a scene and build up an impression of an art work. It is the contention of this paper, speculative as it may be that even without the knowledge of the science; artists over thousands of years have exploited many vision, perception and cognitive traits of humans, of which science has only recently begun to verify. Though beyond the scope of this paper an area that would be interesting to pursue would be to use current eye tracking techniques in a study using high resolution prints of early versus late Rembrandt portraiture and then to analyze the scans in a rigorous way. At the time of publishing, the author has begun such studies using a computational modelling system that utilizes portrait artist's cognitive knowledge [18].

\section{REMBRANDT, EYE MOVEMENT AND INTENT}

With Berger's vocabulary of painting modes, a review of the recent scientific understand of human central focused vision and eye movement theory as well as noting early research into eye movement and observing art, it is now possible to examine the how artists like Rembrandt, might have exploited an intuitive understanding of visual perception to focus the viewer's gaze within their paintings. Virgil Elliott [14] an artist and writer on the technical innovations of Rembrandt states of Rembrandts work that "the highly refined imagery of his younger days gradually gave way to a rougher, more painterly finish in his middle and later years, perhaps due to changes in his eyesight (Figure 6). Could it be instead that a mature Rembrandt, continued his life long critique and discourse with the Italian Renaissance by performatively inventing another, more painterly, technique, one 'more cognizant of his discourse with his viewers', more personal and direct than what Berger has called graphic and optical modes?

The eye-brain loop is significant, intuitive and not very well understood, but it reveals how in real-time, humans can build up a view, i.e. a personal model, of the world in front of us. Our eye-brain loop is constantly re-evaluating our next move in the scene before us - building from nothing, to an impression, to an understandable scene, to our reaction or intention. This is as true for a painter as they are in the act of creating, and evaluating their next painterly move, as it is for an observer of a painting try to take in all they see. Besides more mechanical, planned out artistic methods, both individually and historically, like the painting's narrative, its composition, the use of perspective, as well as his strong use of planned lighting effects, did Rembrandt also use his gesture, his hand and his intuition to guide and persuade the viewer through the image via a more painterly textural level. The textural trace can lie on its own plane but deeply affects the observer's recognition, his personal experience of the graphic and optimal plane of an image - it can setup deep conversation between the artist and the observer. Did Rembrandt's reaction to the Italian Model and more specifically Titian, herald a new textural agency between artist and observer which would be exploited by artists in the following modern era, returning a more human and organic eye back to the gifts of the early modern era? There is much circumstantial evidence to support this claim. Titian innovated several oil painting techniques. Rembrandt was significantly influenced by Titian and even owned some of his work. 


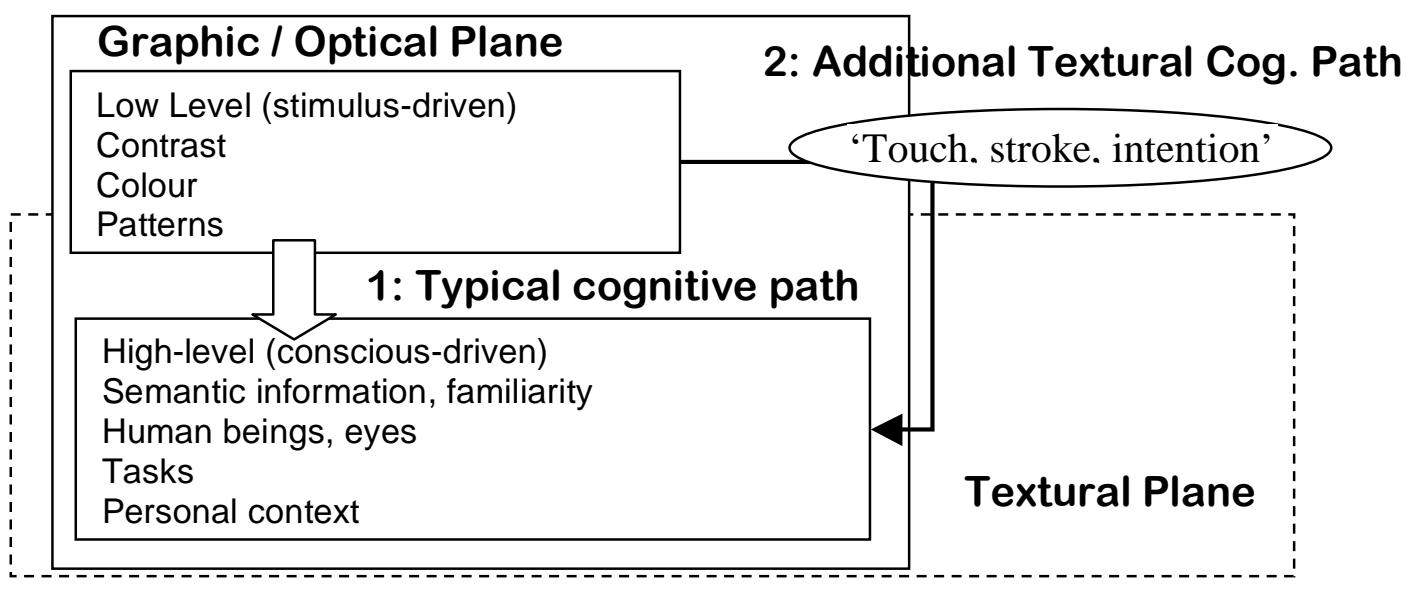

Table 1. Extending on Durand's bottom up cognitive flow, low level constructs (on the textural plane) can affect the viewer's reception of high level semantics in a painting.
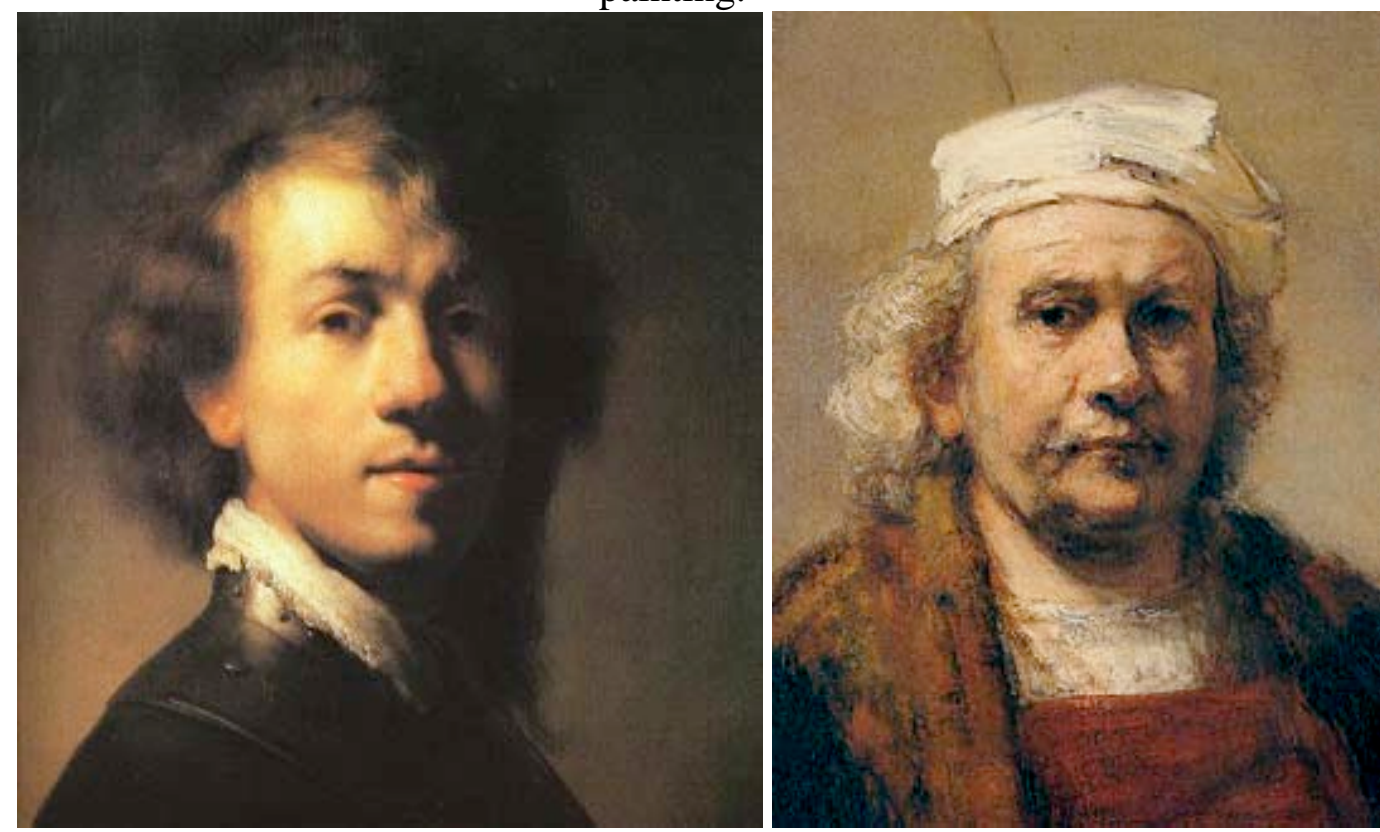

Figure 6. Early self-portrait, 1629 versus a late self-portrait (right), 1661 (close-up). Note increased textural level details (e.g. graduation, edges, and focus differences).

Scanning Rembrandt's late portraits based for modern textural intent and agency techniques that can affect eye movements such as lost and found edges; centre of interest focusing using either tonal, brushwork or contrasts sharpening; pathing techniques via brush direction, highlight edges and blobs, they can clearly be noted in Rembrandt's late work (Figures 7, 8a, 8b). This appears to be less true in Titians late work based on inspection and critical commentary; however more rigorous research is needed. It should also be noted, as seen in the results of Yarbis and Molnar that high level cognitive constructs play an equal or greater role in viewer interest and eye movement, although this area is well documented. This paper specifically attempts to extend the scholarly discussion to low-level textural constructs like edges, contours and sharpness and how they are mediated in real-time by the painters trace. We have also 
limited our analysis to portraiture. Analysis of this kind is fraught with uncertainties as both high and low cognitive areas work in concert with human volition and individuality deeply intertwined in the mix. Extending the work of Durand [15], on his general science of depiction, we show how the textural plane gives artists another direction to affects the high level associative cortex via low level constructs with the uses of more painterly and gestural processes (Table 1).

Using Berger's foundational discourse of optical, and textural painting modes from this essay, along with once again relying on scientific thought, albeit in a new modern form, it seems possible to expand on Rembrandt's appropriation and redefinition of Italian Renaissance ideals to relocate the eye back to its organic origins and, in so doing, demonstrate that other, more mannered forms of artistic agency besides perspective had their origins in this period. Human centralized vision creates our view of the world and with it, our view of art, based on thousands of rapid eye fixations of small visual areas that build up via an elaborate eye-brain recursive loop which then builds an internal model of a cohesive image or scene. Is it possible that artists such as Rembrandt, using optical and textural techniques outlined by Berger and others, can direct and influence the viewer through a painting by exploiting this more organic and intent-driven model of vision? Berger's detailing of his four painting modes in early modern painting system, specifically the optical and textural modes, appears to be a way to parse through this possibility. Berger describes the "overlapping debate about the relative merits of the 'smooth' and 'rough' manners of painting which arise as a response to the drift of the optical toward the textural mode" (p. 499). Once again performatively reacting to Italy and specifically Titian's late work that introduced significant brushwork and bodily trace, we hypothesis that Rembrandt have appropriated and extending Titian technique from just 'texture as material and bodily trace' to 'texture (with optical, as they are interrelated) as a tool for artistic agency and intent' - directing and influencing (Crary's [16]) observer's gaze through a painting, not only through high level cognitive constructs like scenes, people and lighting but through more textural and painterly means (Chart 1). Rembrandt's late portraits seem to display hints of this intended agency through textural tracings, including brushstroke 'centre of interest' focusing techniques and 'lost and found edges.' These brushwork-based, textural plane techniques that coerce and lead the observer's eye through a painting are well noted as standard techniques in late 20th century modern art and portraiture, but are seldom attributed to having their birth in the early modern period or with Rembrandt.

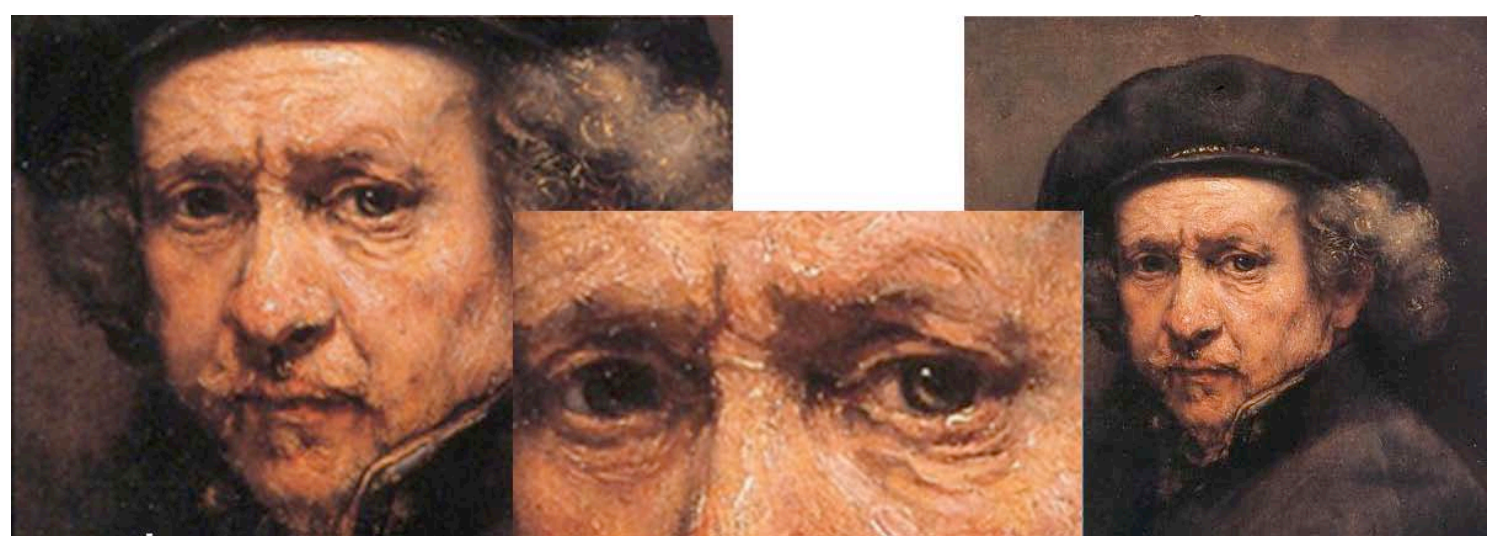

Figure 7. Self Portrait with Beret, 1659. Focused left eye, lost left lower cheek edge $\&$ dark background send viewers eye toward cent of interest. 


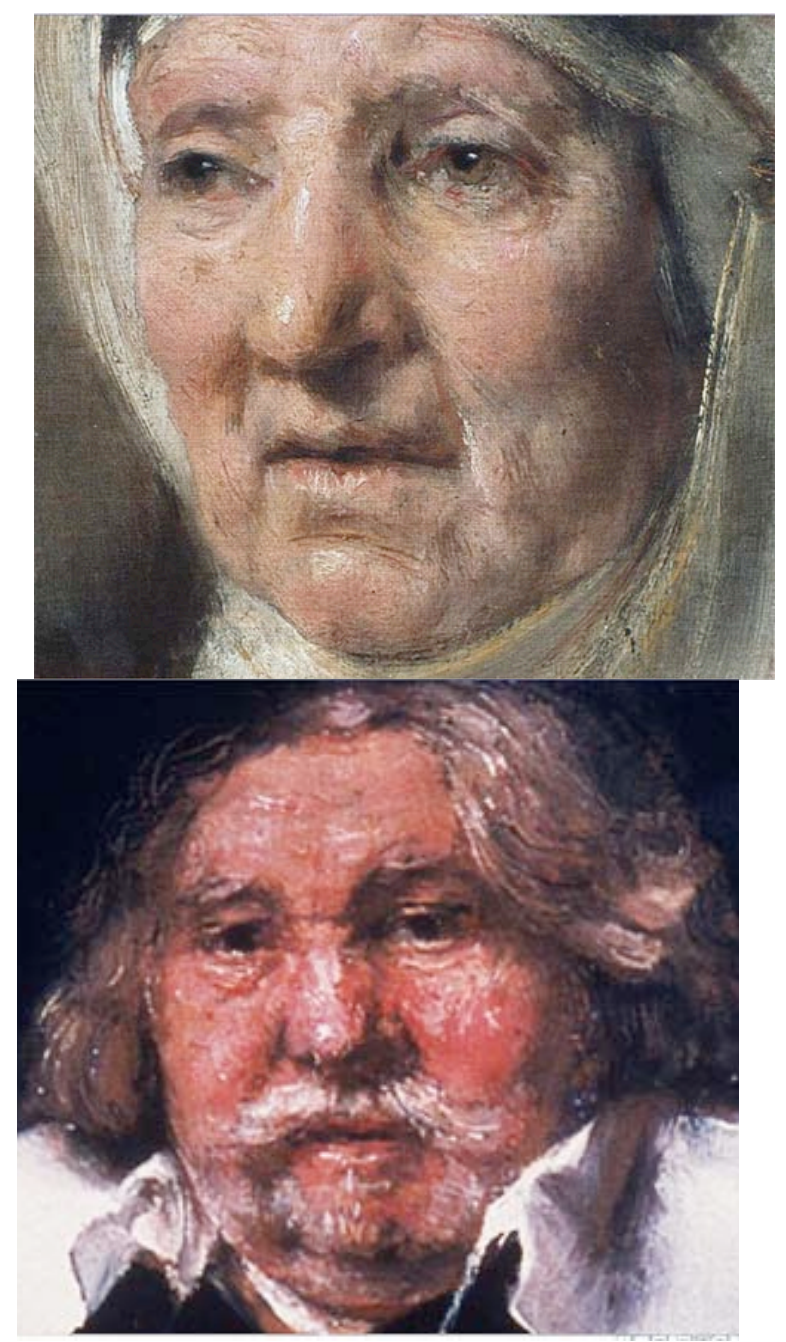

Figure 8. a) Portrait of an Old Lady, 1662. Focused left eye, lines, and contours wrapping the face. b) Elderly Man, 1667. Disjointed highlight lines pull your gaze in all directions, emphasizing a confused almost drunk depiction.

On a modest level, this paper has attempted to extend Berger's textural mode definition to include textural agency and support historians like Berger to return the 'organic eye' through textural agency constructs back to the early modern period via the same scientific thought that obscured in the first place. We are not implying a direct link between the science of human eye movement with late Rembrandt and other artists in the early modern period. We are putting forth a speculative claim that artists, even without a deep knowledge of the science, have intuitively learned to exploit many human vision, perception and cognitive traits in their craft. Using this knowledge and science intertwined with art scholarship, it is possible to bring some clarity to both art and science questions. We then attempt to use these techniques to hypothesis that Rembrandt, reacting to his Italian contemporaries, developed specific painterly techniques, typically not associated with the early modern period, that influence a observers eye-brain modelling of a work, heralding in a deeply intuitive and communicative new technique that artists have embraced thought-out the modern era. 
[1] BERGER JR, H: "The System of Early Modern Painting”, Representations, No. 62, Spring, pp. 31-57, 1998.

[2] JAY, M: "Scopic Regimes of Modernity", Vision and Visuality, ed. Foster, Bay Press, 1988.

[3] ALBERTI, L B: On Painting [First appeared 1435], trans. John R. Spencer, University Press, New Haven, 1956.

[4] HALL, M: Color and Meaning: Practice and Theory in Renaissance Painting, Cambridge University Press, 1992.

[5] SANDEN, J H: Portraits from Life, North Light Books, 2004.

[6] BROWN, H: Harley Brown's Eternal Truths for Every Artist, North Light Books, 2001.

[7] BERGER JR, H: Fictions of the Pose: Rembrandt against the Italian Renaissance, Stanford University Press, 2000.

[8] CLARK, K: Rembrandt and the Italian Renaissance, University Press, 1966.

[9] ROSAND, D: Painting In Cinquecento Venice: Titian, Tintoretto, Veronese, Yale University Press, 1990.

[10] ROSAND, D: "Titian and the Eloquence of the Brush", Artibus et Historiae, Vol. 2, No. 3,1981.

[11] SOLSO, R: Cognition and the Visual Art, MIT Press, 1996.

[12] YARBUS, A: Eye Movements and Vision, Plenum Press, 1967.

[13] MOLNAR, F: "About the role of visual exploration in aesthetics", in HI Day, ed., Advances in Intrinsic Motivation and Aesthetics, 1981.

[14] ELLIOT, V: Traditional Oil Painting: Techniques And Concepts Of Classical Realism From The Renaissance To The Past, Watson-Guptill Publications, 2007.

[15] DURAND, F: The Art and Science of Depiction, Unpublished manuscript, http://people.csail.mit.edu/fredo, 2000.

[16] CRARY, J: Techniques of the Observer: On Vision and Modernity in the Nineteenth Century, MIT Press, 1990.

[17] DIPAOLA, S: A Knowledge Based Approach to Modelling Portrait Painting Methodology, EVA-07: Proceedings of Electronic Imaging \& Visual Arts, 2007. 